\title{
Militancia dentro y fuera de los partidos: nostalgia y adaptación en el compromiso militante en organizaciones oficialistas en Argentina y Brasil desde 2003
}

\author{
Action inside and outside political parties: \\ nostalgia and adaptation in support of \\ official organizations in Argentina and Brazil \\ since 2003
}

\section{Dolores Rocca Rivarola}

\section{Resumen}

A través del relevamiento de material periodístico y de documentos de organizaciones, este trabajo aborda la cuestión de cómo se concibe y experimenta la militancia al interior de las bases de sustentación activa y organizada de los gobiernos brasileros y argentinos desde 2003, dentro y fuera de los partidos políticos de origen de los presidentes. Estas concepciones son analizadas especialmente en relación con el modo en que se manifiesta la referencia al compromiso militante y las identidades políticas en el pasado, advirtiendo un fenómeno doble. Por un lado, se observa una adaptación a condiciones de incertidumbre y volatilidad de la vida política en las propias prácticas políticas cotidianas. Por otro lado, los testimonios de los propios actores exhiben, en cambio, definiciones nostálgicas y apelaciones a un pasado de identidades políticas arraigadas, de partidos (o de su propio partido) teniendo una intensa vida orgánica y con un sostenido y permanente vínculo con el electorado.

\section{Palabras clave}

Militancia Política; Compromiso Político; Partidos; Brasil; Argentina.

\begin{abstract}
As a result of gathering and analyzing journalistic material as well as documents and manifests released by the organizations, this paper approaches the issue of how political activism is conceived and experienced within the active and organized supporting ensembles (in and out of the presidents' party of origin) of the Argentine and Brazilian governments since 2003. Those conceptions are analyzed specially with respect to the way the subjects refer to what political commitment and political identities were like in the past, concluding there is a double phenomenon. On one hand, there is an adaptation, in their own and every-day political activities and practices, to an environment defined by uncertainty and volatility. On the other hand, they express nostalgic definitions and references to a past in which political identities were allegedly stable, and parties (or their own party, at least) had an intense organic life and a permanent bond with voters.
\end{abstract}

\section{Keywords}

Political Activism; Political Commitment; Parties; Brazil; Argentina. 


\section{Introducción}

La militancia oficialista puede aparecer a simple vista como una cuestión ampliamente abordada desde las ciencias sociales en los últimos años. En Argentina, existen numerosos estudios referidos a las organizaciones sociales y políticas que volcaron su apoyo a Néstor Kirchner a partir de 2004 e incluso a otras surgidas al calor de su gobierno, nacidas ya con el propósito explícito de sustentar al presidente. En Brasil ha sido también considerable la cantidad de trabajos dedicados a analizar al PT, la CUT, el MST y la base parlamentaria aliada al gobierno de Lula a partir de su victoria electoral en 2002 y asunción en 2003. Distintos argumentos han sido postulados, de ese modo, en torno al origen y la evolución de la relación con el gobierno. La presente observación de la militancia oficialista parte de otro tipo de interés e interrogantes.

Se apunta a identificar las concepciones sobre la militancia política y el compromiso militante que exhiben tanto activistas como dirigentes de organizaciones oficialistas a través de una contextualización en un escenario de intensa fluctuación de las identidades y alineamientos políticos, y de partidos que han perdido su capacidad para generar lazos identitarios duraderos con el electorado. Así, se procura relacionar las nociones sobre la militancia actual presentes en estos actores con el modo en que los mismos conciben o imaginan la militancia en el pasado, y con las propias características o trayectoria de la organización de pertenencia, postulando el argumento de un fenómeno de carácter doble: tanto de adaptación como de nostalgia. A través del relevamiento de material periodístico y de documentos elaborados por las propias organizaciones, entonces, se plantearán algunas observaciones en torno a la cuestión de cómo se concibe y experimenta la militancia (actual y en relación con la imaginada o recordada del pasado) al interior de la bases de sustentación activa y organizada de los gobiernos brasileros y argentinos desde 2003 (momento de asunción de Lula y de Kirchner).

Dos ejes han organizado el análisis del material consultado en torno a las concepciones sobre la militancia: I) su contextualización en un escenario de volatilidad electoral en el que desarrollan su actividad política - escena caracterizada por la fluctuación de las identidades políticas y por una desafección del electorado respecto de los partidos -; II) partiendo de aquel contexto descripto, la relación con y la referencia al modo en que se llevaba adelante la militancia y el compromiso en el pasado.

\section{Contextualización: volatilidad electoral y fluctuación de los vínculos políticos}

El proceso de declinación de los partidos políticos, no sólo en las dimensiones de su conjunto de afiliados, sino también en su capacidad de suscitar en el electorado identidades partidarias y un voto constante, ha recibido considerable atención de las ciencias sociales y, especialmente, la ciencia política. 
No es el objetivo de este trabajo reconstruir esa agenda de investigación, dado que en trabajos previos (ROCCA RIVAROLA, 2010) ha sido presentado ya un estado del arte recorriendo varios de aquellos estudios, así como también han sido relevadas investigaciones que han examinado el compromiso militante y la militancia como actividad, tanto en el campo académico francés y anglosajón como en Argentina y Brasil, los dos casos de la presente indagación (ROCCA RIVAROLA, 2013a). Ambas revisiones combinadas han procurado dar cuenta de las condiciones actuales del vínculo entre representantes y representados en Argentina y Brasil para eventualmente asociarlas con las características que asumen las concepciones acerca de la militancia presentes, en ese contexto, en sus propios protagonistas.

Hay algunos puntos especialmente relevantes, de todos modos, que cabría enumerar como parte de una contextualización que contribuya a la comprensión del escenario particular en el cual se analizarán las concepciones acerca de la militancia en ambos casos nacionales.

En primer lugar, si definimos a la identificación partidaria en directa relación con la vigencia de un voto constante (y unificado entre los distintos niveles) al partido de preferencia a lo largo de sucesivos procesos electorales y la escasa manifestación de fenómenos como la defección partidaria (GREENE, 2004), podemos advertir que esos indicadores han sido manifiestamente sacudidos por mutaciones en el formato representativo - mutaciones que Manin (1992) denominará como una "metamorfosis" o "desplazamientos y reacomodos" más que una crisis (un creciente número de electores que vota de modo diferente en cada elección, la negativa a identificarse con algún partido político, etc.). Montero y Gunther (2002, p. 14) argumentarán, en ese sentido, que ha habido un debilitamiento de "los vínculos estructurales y psicológicos entre los partidos y los ciudadanos".

En segundo lugar, en ese escenario de transformaciones en los partidos políticos y en el ambiente en el que éstos actúan (debilidad de los históricos actores colectivos, procesos de individuación del electorado, y menor confianza de la ciudadanía en los partidos), asistimos a la emergencia de líderes que construyen un lazo representativo teniendo como destinatario directo a la ciudadanía, con independencia de las mediaciones partidarias o flexibilizando la relación con sus partidos de origen (NOVARO, 1995; ARMESTO y ADROGUÉ, 2001; CHERESKY, 2007; FABBRINI, 2009). Un ejemplo de las repercusiones de este último fenómeno era, en Brasil, la imposibilidad, que los propios militantes del PT advertían ${ }^{1}$, de que, a la par del ascenso en la popularidad personal de Lula como presidente se produjera un correlato de crecimiento similar del PT (es decir, constataban que aunque el "petismo" había crecido en los años del primer mandato de Lula, no lo había hecho proporcionalmente al avance del "lulismo").

\footnotetext{
${ }^{1}$ Entrevistas realizadas para tesis doctoral a militantes y dirigentes del PT en San Pablo y Río de Janeiro en 2008 y 2009, respectivamente.
} 
Ello se observaba, asimismo, en la notable distancia entre los votos obtenidos en el nivel presidencial en cada región y el caudal electoral recibido por los candidatos del PT en los cargos legislativos o en los niveles estaduales y locales en esos mismos distritos, diferencia de la que ha dado cuenta Ribeiro (2008) ${ }^{2}$. Los últimos años, de todos modos, estarían exhibiendo un cierto crecimiento del caudal electoral recibido por los distintos candidatos del PT en los Estados. En Argentina, el denominado efeito carona (efecto arrastre) se producía con menor dificultad que en Brasil. Por ejemplo, la lista del Frente para la Victoria - sello electoral impulsado por el presidente Kirchner - a diputados nacionales ganaba, en las elecciones de 2007, en las ocho secciones que integran la provincia de Buenos Aires; y las listas a diputados y senadores provinciales también salían victoriosas en todas las secciones menos la Octava (La Plata). Vale aclarar, sin embargo, que esa traducción o transferencia de votos no era de Kirchner al sello PJ sino al sello electoral que el presidente impulsó como propio en esa provincia durante su gobierno (Frente para la Victoria). El PJ como organización no ha experimentado un crecimiento (en cantidad de afiliados, presencia barrial y territorial, etc.) durante los hasta ahora tres gobiernos kirchneristas (Néstor Kirchner: 2003-2007, Cristina Fernández de Kirchner 2007-2011 y 2011-2015) que vaya de la mano de la popularidad presidencial. Incluso, la revitalización del apoyo al gobierno y de la popularidad de Cristina Fernández de Kirchner luego de la muerte de Néstor Kirchner ${ }^{3}$ se tradujo más bien en un crecimiento sideral de otras organizaciones (no del PJ), sobre todo de la agrupación La Cámpora en términos de sus dimensiones, presencia territorial, presencia en cargos estatales.

En tercer lugar, cabe establecer una oportuna distinción entre el caso argentino y el brasilero: la fisonomía de la representación descripta para Argentina como producto de transformaciones recientes (electorado disociado de los partidos políticos, identidades políticas fluctuantes, sellos partidarios cambiantes, etc.), en Brasil, en cambio, ha sido presentada como asociada íntimamente al propio sistema (MAINWARING, 1999; POUSADELA, 2007) y no como un fenómeno acaecido en las últimas décadas. Ahora bien, lo ocurrido allí a partir de la transición democrática (1985) con el vínculo entre los partidos y la ciudadanía ha

\footnotetext{
${ }^{2}$ En 2002, mientras que Lula era votado por un 46,4\% del electorado (en la primera vuelta), sólo un $18,4 \%$ votaba al PT para diputados nacionales, y sólo un $25,3 \%$ a la alianza electoral que acompañaba al presidente. En 2006, Lula se llevaba un 48,6\% de los votos en el primer turno, mientras que el PT obtenía un $15 \%$ a diputados nacionales, y la alianza electoral oficialista un $17,3 \%$. Y en cuanto a los gobernadores petistas, sólo había tres después de 2002 y cinco después de 2006 - sobre un total de 27 Estados. Las cifras fueron obtenidas de cuadros elaborados por Santos y Vilarouca (2008) y también por Ribeiro (2008), a partir de datos suministrados por el Tribunal Superior Electoral (TSE) de Brasil.

${ }^{3}$ En torno a esa revitalización, uno de los directores de la consultora de opinión pública Poliarquía decía: "En la presidencia de Cristina Kirchner le quitó muchos puntos la crisis del campo, la recuperación de 2010-2011 le sumó 15 puntos de imagen positiva y la muerte de Néstor Kirchner le dio en un mes un salto de 20 puntos de popularidad". (CATTERBERG, 2012).
} 
sido motivo de debate académico. Mientras que algunos autores han anunciado en los últimos años una institucionalización y consolidación del sistema de partidos (SANTOS y VILAROUCA, 2008), otros trabajos han señalado, en cambio, una intensificación de esas tendencias (HOCHSTETLER y FRIEDMAN, 2008). Esa intensificación ha sido argumentada especialmente para los años posteriores a 2002, cuando Lula fue electo, advirtiendo una creciente desafección con los partidos en general (PAIVA, BRAGA y PIMENTEL, 2007), una disminución del número de electores que exhibían preferencias o sentimientos partidarios (CARREIRÃO, 2008), y el desarrollo de vínculos menos ideológicos y programáticos entre los partidos y el electorado (MAINWARING y TORCAL, 2005). De todos modos, referirnos para ambos casos nacionales a una escena de fluctuación en los alineamientos políticos y de volatilidad electoral no implica omitir los marcados contrastes, por ejemplo, en lo que respecta al Partido Justicialista (PJ) y al Partido dos Trabalhadores (PT): sus legados militantes, su vida interna y funcionamiento actual $^{4}$, su lugar dentro del conjunto oficialista ${ }^{5}$ en cada país, y su relación con el gobierno. Aunque ambos escenarios están caracterizados por la volatilidad, la vida orgánica actual de ambas fuerzas políticas es bien diferente, lo cual se evidencia, por ejemplo, en los sitios web respectivos, con la abundancia de reuniones y documentos emitidos y publicados por el Directorio Nacional del PT, y, por otro lado, la escasez (casi ausencia) de instancias de reunión, comunicados y declaraciones del PJ nacional. El PT ha sostenido como partido una vida interna, un funcionamiento de sus autoridades (y procesos de selección de las mismas), pronunciamientos públicos como unidad política - y en ese sentido, la afiliación tiene consecuencias concretas, lo cual se vio en la expulsión del partido de parlamentarios del PT que habían devenido oposición al primer gobierno de Lula en 2003 -, una continuidad de su sello en todo el territorio nacional brasilero para los distintos procesos electorales y para el funcionamiento de su bloque parlamentario, etc. Ello no significa tampoco afirmar que predomine en Brasil un voto na legenda (voto por el sello, más allá del candidato que se presente por el partido) o una efectiva identidad partidaria que el PT haya logrado suscitar en la gran mayoría del electorado. Pero sus características organizativas y su funcionamiento interno distan de parecerse al

\footnotetext{
${ }^{4}$ Una de esas diferencias es la que nos ha llevado a denominar a sostener en trabajos previos que el término "partido" ni siquiera es adecuado ya para pensar al PJ (aunque sí al PT), al que podríamos describir mejor como "redes disgregadas" (ROCCA RIVAROLA, 2011).

${ }^{5}$ El uso del término oficialismo (ROCCA RIVAROLA, 2011) ha sido un modo de abordar las bases de sustentación organizada de los presidentes Luiz Inácio Lula da Silva, en Brasil (primer mandato), y Néstor Kirchner, en Argentina, distinguible de las nociones de partido oficial y de coaliciones partidarias. El oficialismo refiere al conglomerado de sectores organizados que fueron confluyendo, alejándose y realineándose en torno de las figuras de Kirchner y Lula (y luego de Fernández de Kirchner, y Rousseff); la base organizativa en la que se sostenía el presidente, y cuyas organizaciones y espacios políticos desarrollaron manifestaciones públicas de apoyo a la política oficial o a la figura misma del primer mandatario.
} 
estado de disgregación y atomización en el que se encuentran en la actualidad las redes del $\mathrm{PJ}^{6}$, estado que no puede ser comprendido bajo el argumento de que el peronismo siempre tuvo una dinámica movimientista. Ello porque no se trata de la presencia o ausencia de reglas partidarias de funcionamiento interno o de una institucionalización partidaria, sino del desarrollo de una vida interna permanente y del peso como actor organizado dentro del gobierno. A modo de ejemplo ilustrativo, un fenómeno como la acelerada proliferación de la presencia de la agrupación La Cámpora (surgida al margen del PJ) dentro del Estado nacional (cargos, recursos, posicionamiento en listas legislativas) y su meteórico crecimiento dentro del conjunto oficialista ha sido posible dadas las dinámicas internas del oficialismo kirchnerista, mientras que sería difícilmente concebible un proceso similar al interior del oficialismo de Lula o el de Dilma ${ }^{7}$.

En cuarto y último lugar, hay una característica que ha sido señalada en trabajos propios previos como característica de las dinámicas internas de los oficialismos en Brasil y Argentina desde Lula y Kirchner (ROCCA RIVAROLA, 2013b) que podría estar incidiendo de algún modo sobre el modo en que militantes y dirigentes de organizaciones y espacios al interior de estos conjuntos construyen sus nociones sobre la militancia oficialista. Aun en el caso de aquellas fuerzas políticas, organizaciones y espacios que se consideraban a sí mismas el núcleo más leal al presidente, tanto en Argentina como en Brasil se observaba la noción entre los propios actores de la ausencia de un espacio estratégico de articulación y coordinación entre esas fuerzas en el marco del gobierno, de un mecanismo que organizara de ese modo la dinámica interna del oficialismo, y que habilitara de modo más permanente para aquellos actores colectivos la posibilidad

\footnotetext{
${ }^{6}$ El PJ fue intervenido por la Justicia en 2005 y hasta 2008 permaneció acéfalo y sin reuniones de sus autoridades provinciales. Durante el gobierno de Kirchner se produjeron diferentes (y hasta opuestas) manifestaciones y pronunciamientos públicos de grupos y redes identificadas como parte del partido. La utilización del sello PJ no tuvo tampoco una continuidad ni pautas coherentes y sostenidas entre los distintos procesos electorales durante el período: fue utilizado en algunas provincias u ocasiones como el sello oficialista, como sello opositor a Kirchner, y también como actor, entre otros, dentro del sello oficialista "Frente para la Victoria". Durante el mandato de Cristina Fernández de Kirchner se llevó adelante un proceso que suponía una normalización del partido, con la designación de Néstor Kirchner como su presidente y procesos de internas partidarias en la provincia de Buenos Aires. Sin embargo, esos eventos no derivaron en una reactivación y reposicionamiento del $\mathrm{PJ}$ en el esquema del oficialismo kirchnerista. El reclamo del entonces vicepresidente del PJ de la provincia de Buenos Aires, Hugo Moyano, en diciembre de 2011, de que éste se había convertido en una "cáscara vacía" daba cuenta no sólo de la distancia entre este dirigente y el gobierno sino también entre las expectativas de las redes del PJ respecto del proceso de reorganización del partido y sus resultados.

${ }^{7}$ Los cargos ocupados por miembros de La Cámpora en el Estado - los que este trabajo ha identificado hasta ahora -, aunque muy numerosos, no son ministeriales sino por debajo (un viceministro, y luego siete secretarios, 11 subsecretarios, 15 directores/presidentes/titulares de organismos como la SIGEN, TELAM, CANAL 7, de algunas empresas estatales como Aerolíneas Argentinas, etc.).
} 
de incidir en tanto tales sobre la orientación del gobierno ${ }^{8}$. Un paso posible hacia una superación de esa ausencia fue en Brasil, la creación del denominado Consejo Político (Conselho Político) en el segundo mandato de Lula. El mismo fue presentado formalmente como un espacio de discusión y relacionamiento de las distintas fuerzas políticas con el presidente. De todos modos, distintos actores de los partidos aliados entrevistados en su momento identificaban serias limitaciones en su potencialidad y en tanto ámbito de posible incidencia de los partidos de la base oficialista sobre las decisiones del gobierno. En Argentina, el lanzamiento por parte de Cristina Fernández de Kirchner en 2012 del espacio denominado "Unidos y Organizados", en el que parecían aglutinarse aquellas organizaciones y movimientos que no eran parte del Partido Justicialista, sino que se encontraban más bien dispersos entre sí en su apoyo al gobierno kirchnerista, tal vez sea un fenómeno algo reciente para poder identificar su potencialidad para devenir una fuerza estructurada o una instancia de coordinación interna y articulación cotidiana $^{9}$. De todos modos, el proceso de conformación de las listas para las elecciones Primarias Abiertas, Simultáneas y Obligatorias (PASO) en 2013 no mostró a Unidos y Organizados actuando como un espacio orgánico y en funcionamiento coordinado al interior del oficialismo que lograra posicionarse en las listas legislativas como tal ${ }^{10}$.

La militancia oficialista que analizamos, se desarrolla, entonces, en el marco de un escenario político marcado por la fluctuación y al interior de conjuntos oficialistas con dinámicas informales y escasamente pautadas, todo lo cual configura un contexto particular en que los militantes y dirigentes de las organizaciones, movimientos y espacios que integran ese conjunto construyen y reconstruyen sus nociones acerca de la militancia política como actividad. Ahora bien, dado ese contexto actual, ¿qué referencias a las características de la militancia en el pasado se formulan desde estos actores colectivos y sus miembros?

\footnotetext{
${ }^{8}$ Tan sólo a modo de ilustración, los entrevistados para la investigación doctoral en Brasil se quejaban de Lula no armaba, no abría espacios de articulación o de coordinación entre las distintas fuerzas y organizaciones que lo apoyaban activamente. Y en Argentina, sostenían que el kirchnerismo no se conformaba como fuerza estructurada, que no existía un ámbito de conducción donde los distintos sectores pudieran coexistir y fueran tratados como unidades orgánicas.

9 Antes, una iniciativa con algunos elementos en común (aunque más parcial) tuvo lugar en 2004 con el lanzamiento del Frente Patria para Todos, que incluía a las organizaciones sociales kirchneristas de mayores dimensiones, el FTV, Barrios de Pie, el MTD Evita y el Frente Nacional Transversal y Popular. Pero aquello no se tradujo en la construcción de un espacio de coordinación común, articulación o cooperación permanente entre las mismas.

${ }^{10}$ El desarrollo de la campaña en la calle, en cambio, sí parece exhibir una coordinación interna mayor de este espacio, aunque no como inclusivo de todos los sectores dentro del oficialismo.
} 


\section{La referencia a la militancia en el pasado}

¿Por qué relacionar las visiones sobre la militancia que procuramos analizar al interior de las organizaciones oficialistas con la interpretación que estos actores colectivos - y sus miembros activos, por supuesto - realizan respecto de las características de la militancia en el pasado? Porque subyace a esta indagación la noción de que las transformaciones antes detalladas y el formato resultante han impactado sobre las visiones que militantes y dirigentes oficialistas tienen sobre la militancia. Esos actores habrían experimentado una adaptación a esas condiciones de la vida política en sus propias prácticas políticas cotidianas. Esa adaptación, sin embargo, no se observaría del mismo modo en su discurso de cara al resto de lo que podríamos llamar el mundo político activo (militantes y dirigentes políticos). En ese discurso o testimonios, aparecerían, en cambio, definiciones nostálgicas y apelaciones a un pasado de identidades políticas arraigadas, de partidos (o de su propio partido) que tenían una intensa vida orgánica y con un sostenido y permanente vínculo con el electorado.

En el caso argentino, la referencia nostálgica apuntaría a un pasado de identidades partidarias, aun en un contexto de normalidad institucional intermitente (debido a los golpes de Estado que caracterizaron el escenario político argentino durante gran parte del siglo XX). Y aunque el peronismo, por ejemplo, se caracterizó a lo largo de su historia por autodefinirse a través de un formato organizativo más movimientista que partidario (PERÓN, 2006 [1952]; LEVITSKY, 2003) - luego, en los años ochenta la fracción autodenominada "renovadora" abogaría por su institucionalización en tanto "partido" (GARCÍA y MONTENEGRO, 1986; ALTAMIRANO, 2004; GORDILLO y LAVAGNO, 1987) -, la capacidad del PJ para configurar identidades políticas duraderas, para mantener un electorado propio y estable a lo largo de los años y asegurar ciertos niveles de disciplina interna no era menor que la descripta por los autores clásicos de la Ciencia Política para los partidos de masas tradicionales. Todo ello, sin embargo, fue experimentado profundos cambios, iniciados en forma incipiente a partir del retorno a la democracia (1983), e intensificados con la crisis de 2001.

En el caso de Brasil, aunque, como ya vimos, los períodos previos a la transición democrática no pueden ser descriptos del mismo modo que en Argentina, con identidades partidarias afincadas en los votantes, el pasado al que las referencias nostálgicas de militantes y dirigentes pueden aludir es el propio pasado del PT, período de intensa militancia barrial, sindical, intelectual (y hasta parroquial, en el marco de las comunidades eclesiásticas de base o CEB, que apoyaban activamente al PT), en el marco de un partido heterogéneo de tendencias internas, de organización en núcleos de base ${ }^{11}$, y que apuntaba a

\footnotetext{
${ }^{11}$ Los núcleos de base empezaron como pequeños grupos de personas (desde 21) que podían organizarse por barrio, por lugar de trabajo, por categoría de trabajo, o por movimiento social. Estos cuerpos o mecanismos han sido estudiados, entre otros, por Guidry (2003), Amaral (2010a) y Roma (2006).
} 
generar en el electorado un lazo identitario que el resto de las fuerzas políticas no estaba generando con la transición democrática.

Es decir, en ambos casos nacionales, existe un pasado, al menos para algunos de los actores del oficialismo, en el que la militancia parecía desarrollarse en otras condiciones (no sólo para quienes la vivieron personalmente como generación sino para quienes imaginan o han tenido acceso a un relato de la misma). Asistimos, entonces, a un fenómeno doble.

Por un lado, se advierte cierta adaptación práctica a esas nuevas circunstancias. Podríamos postular tres ejemplos. En primer lugar, el prolífico desarrollo de redes de militancia virtual (redes sociales, blogs, etc.) que, en el caso del kirchnerismo, han sido estudiadas por Garrido (2012). Para la autora, la militancia online en redes sociales de consumo masivo (Cibermilitancia), por parte de activistas kirchneristas, no ha sustituido, de todos modos, a la militancia más tradicional o territorial sino que termina funcionando como soporte paralelo o complemento directamente vinculado con aquélla ${ }^{12}$. Es un dato significativo, en el mismo sentido del desarrollo de estos nuevos mecanismos de militancia, el hecho de que la mayoría de las organizaciones en cuestión tengan su propio sitio web con mucha documentación propia online (comunicados, manuales de formación para militantes, textos teóricos o de coyuntura de sus referentes, etc.). O que, en el caso del PT, por ejemplo, las autoridades del partido hayan organizado distintos encuentros online con militantes para desarrollar, discutir y socializar pautas de "militancia virtual".

Un segundo ejemplo - que inspiró parte del título del presente artículo -, presente en el caso argentino, aunque no en el brasilero, es el hecho de que se ha generalizado un modo de militancia política oficialista que no se plasma estrictamente bajo la forma de partidos políticos, sino de espacios reticentes a organizarse en términos partidarios y que tampoco llaman a sus miembros a afiliarse a algún partido ya existente. La participación activa y pertenencia a estos espacios aglutinados dentro del oficialismo no ha implicado, entonces, la construcción de un partido propio ni la incorporación a otro. Así, los candidatos a cargos legislativos electos dentro del sello Frente para la Victoria (sello electoral impulsado por el gobierno) en las elecciones de 2005, 2007, 2009 y 2011 no pasaban a pertenecer a algún partido político que funcionara como tal. No había un correlato de afiliación partidaria ni de inscripción formal en una organización partidaria más allá de su reivindicada pertenencia al oficialismo, al "proyecto nacional". El modo, por ejemplo, en que la organización KOLINA, fundada en

\footnotetext{
${ }^{12}$ En sentido similar se pronunciaba, Alexandre Texeira, un militante petista bloguero en una entrevista realizada por el partido y subida al sitio web oficial del PT nacional: "No soy partidario de un trabajo de militancia sólo virtual, creo que el trabajo de la militancia virtual favorece al trabajo de la militancia más tradicional en el sentido que le da velocidad, reduce el tiempo de transmisión de la información [...] La militancia virtual se suma a la militancia física". (TVPT, 2012).
} 
2010 y liderada por Alicia Kirchner, hermana del ex presidente Kirchner, se autodefinía en su sitio web (KOLINA, 2013), es ilustrativa de ese nuevo tipo de inscripción y pertenencia que ha proliferado al interior del oficialismo kirchnerista en la última década: la "corriente" se considera a sí misma un "espacio político del movimiento nacional en todas las provincias del país", y sostiene, con una noción que habilitaría múltiples pertenencias, que "quienes participan [en Kolina] no pierden su identidad ni la de su agrupación, ni la de su movimiento o partido, pues se amalgaman en una corriente militante".

Lo cierto es que gran parte de la militancia oficialista durante el kirchnerismo parece haberse desplazado por fuera del Partido Justicialista y de otros sellos partidarios que integran el oficialismo (Frente Grande, Partido Intransigente, Partido Comunista Congreso Extraordinario, etc.), para expresarse en forma de corrientes (Kolina, Corriente Peronista Descamisados, Corriente Nacional de la Militancia - en la cual se agruparon varios referentes y legisladores de la transversalidad y otros provenientes antiguamente del PJ, etc.), movimientos (MILES, Movimiento Evita, Movimiento Libres del Sur - hasta su distanciamiento del gobierno - y Frente Transversal Nacional y Popular) y agrupaciones (no en el sentido de las agrupaciones peronistas tradicionales formalmente enmarcadas en el PJ, sino más bien en la orientación propia de La Cámpora y otras).

En tercer lugar, y tal como han observado otros trabajos acerca de la militancia en las últimas décadas, sus protagonistas establecen vínculos y compromisos flexibilizados o efímeros. En su tesis acerca de las transformaciones organizativas del PT en Brasil a partir de la década del noventa - y observando particularmente los ya mencionados núcleos de base y el proceso de elecciones directas de autoridades partidarias (PED) -, Amaral (2010b) argumenta, paralelamente a un crecimiento en la base de afiliados del PT, alteraciones en las formas de militancia y la construcción de prácticas de militancia de menor intensidad (aunque más inclusivas) que las halladas en el período de formación del partido. También son sugerentes, en cuanto a este fenómeno de compromisos adaptados a un presente de fluctuación, los argumentos de Rocha (2008 y 2009), que ha estudiado los contrastes y los puntos de confluencia entre la militancia del PT en el pasado y la militancia actual a través de la observación de los jóvenes del partido en el Estado de Brasilia. La autora advierte una creciente fragmentación y diversidad en los vínculos actuales y describe algunas tendencias significativas en las lógicas organizativas producto de la llegada al poder: la diversificación de los modos de adhesión al partido, sobre la base de vínculos más individualizados con líderes y candidatos específicos, y el declive, en cambio, de vínculos y recursos colectivos ${ }^{13}$.

\footnotetext{
${ }^{13}$ Las transformaciones experimentadas por el PT hasta su llegada al poder han recibido mucha atención en las ciencias sociales brasileras. Para un estado del arte sobre trabajos que han abordado esas transformaciones, ver Amaral (2010a).
} 
Por otro lado, y como anticipábamos, al tratarse de un fenómeno doble, hay otra cara del mismo paralela a la adaptación. Posiblemente como resultado de una idealización de la militancia en el pasado, aparecería un contraste recurrente en el discurso al interior del ambiente militante entre el supuesto estado de la militancia en la actualidad y el modo en que se recuerda o se piensa que la misma era hace tres décadas o más, con la casi mítica figura del "militante de antes", dispuesto a hacer cualquier actividad (desde ocupar un cargo estatal decisivo y representar a su organización en reuniones clave con otros sectores, hasta pintar una pared o repartir volantes de la organización en algún ámbito de base). El testimonio de Octavio, miembro del Movimiento Evita, e iniciado en la militancia a fines de los años 1970, ilustraba esa lectura. En palabras de Octavio:

Los niveles de compromiso son distintos. Cuando empecé a militar me agarró... la primera persona que a mí me condujo fue la última pareja de Norma Arrostito [reconocida militante de la organización armada Montoneros]. Venía el compañero y me decía "tenés que agarrar una brocha e ir a pintar toda la ciudad", y yo iba y lo hacía. Pero ahora no hay ni uno de ésos. Y el compañero [se refiere a él mismo] está viejo ya (risas). Entonces, no hay niveles de representación que permitan un "porque te lo digo yo"... Segundo porque los pibes de ahora tienen menos niveles de formación, te discuten más, te mandan al carajo [...]. Yo lo que noto es que es muy difícil, además, para muchos compañeros, sobre todo los más jóvenes, pensar colectivamente. Uno dice siempre que no tiene que importar quién va (para un cargo), pero eso implicaría tener una estructura colectiva con la cual realmente no importa quién vaya en serio, porque va "en nombre de"....cuando yo empecé a militar nosotros nos peleábamos por no ir al Consejo Federal, porque nos parecía que ahí estaban los burócratas, que la militancia estaba en los barrios, que había que quedarse ahí. Y hoy en día se matan por ir a cualquier reunión.

Asi mismo, el pasado sería recordado o imaginado por parte de estos militantes como un momento en el que las reglas del juego partidario y electoral tenían un carácter más previsible y asociado al mundo de la militancia que en la actualidad, en la que primarían la incertidumbre de los escenarios políticos respecto del mediano y hasta corto plazo, y la volatilidad, no sólo en el voto del electorado, sino en los alineamientos de la propia dirigencia. A modo de ejemplo, Salvador, dirigente de redes locales del PJ en el norte del conurbano, decía en 2009: 
En algún momento, la política tenía valoraciones. La Argentina tenía un alto nivel de movilización política y de participación, en las dictaduras. El advenimiento de la democracia hizo del valor de la lealtad una cosa muy rígida, se militaba sin esperar cargos partidarios porque no se los conocía. [...] El cargo era ser jefe de militantes y que la gente reconociera a alguien como dirigente político. [...] Pasamos de una lealtad absolutamente inflexible, que era la lealtad significaba la muerte, a una lealtad moral o ética o partidaria, pónganle el título que quieran, a una lealtad financiada, en un momento en una estructura en la que si no tenías recursos no podías participar de la interna porque en realidad la lealtad - no es comprada porque no alcanza la palabra - estaban cercadas por el poder. Hasta un escenario donde la lealtad es la excepción, como es hoy. Hoy es exactamente al revés. Y que en muchos casos tiene que ver con la flexibilidad de la norma. O sea, a ver, cuál es el mérito de ser leal si uno no sabe en realidad cómo va a ser el proceso de selección de candidaturas dentro de seis meses. Nadie te garantiza nada. Se los pongo en términos prácticos, ¿Por qué los concejales míos de mi distrito van a seguir estando conmigo si en realidad no saben cómo va a ser el proceso de selección de candidaturas? [...] Tendrás un trabajo... o serás funcionario municipal y tendrás alguna manera de seguir zigzagueando, en un escenario donde, insisto, los límites entre los partidos son muy bajos.

En Brasil, esa nostalgia también se advertía en los relatos de militantes y ex dirigentes petistas, especialmente en torno al desarrollo militante que el PT solía tener. Así, Virgílio, militante histórico del PT de Río de Janeiro, entrevistado en 2009, y Baltasar, dirigente del PT en la misma ciudad, afirmaban:

Virgílio: Antiguamente había núcleos, estaban los periódicos del PT, que eran como organismos de reunión, tenían una vida muy activa, muy activa. Hoy no hay nada. Las direcciones regionales [direcciones por región, por barrio] son un chiste, no funcionan. [...] Entonces el PT es una inmensa cáscara vacía en tanto estructura orgánica. La dirección nacional, la dirección estadual, la dirección municipal, que funcionan mal, al menos funcionan. Son instancias de poder. Pero no hay vida orgánica de debate entre la militancia.

Baltasar: Hasta la década del 1990 había una vida común entre las tendencias en los núcleos de base, de hacer un debate político desde la situación del barrio hasta la dirección nacional. [...] Eso cambió mucho.

\section{Observaciones finales}

Este trabajo ha explorado algunos aspectos vinculados con la militancia oficialista en Brasil y Argentina desde las presidencias de Lula y Kirchner, como base para profundizar - a través de la realización futura de entrevistas semiestructuradas a los propios actores - el análisis sobre el modo en que 
militantes y dirigentes de organizaciones oficialistas construyen y explicitan sus concepciones sobre la militancia política en organizaciones oficialistas. Para ello se ha valido de un primer relevamiento de material periodístico y documentos elaborados por distintas organizaciones que conforman el conjunto oficialista alrededor de Cristina Fernández de Kirchner y Dilma Rousseff. También se han vuelto a consultar entrevistas realizadas - entre 2005 y 2010 - a militantes, dirigentes y legisladores para una investigación previa acerca de las definiciones de pertenencia al oficialismo dentro de las bases de sustentación activa y organizada de los gobiernos de Lula y Kirchner.

Las observaciones formuladas en este trabajo, entonces, se han organizado a partir de dos ejes. En primer lugar, se ha presentado una contextualización de la cuestión de las concepciones acerca de la militancia oficialista, haciendo foco en algunos elementos propios de un escenario de volatilidad electoral y fluctuación activista en el que estos actores desarrollan su actividad política y que incidiría sobre sus concepciones acerca de ese compromiso militante. En segundo lugar, se han postulado algunos argumentos en torno a la referencia al pasado en las definiciones sobre la militancia y el compromiso, en el marco de una hipótesis más general sobre el modo en que los actores se adaptarían en la práctica a las condiciones del escenario político-electoral y exhibirían paralelamente una visión nostálgica (en recuerdos o imaginada, según su generación de pertenencia) respecto de un pasado de identidades partidarias arraigadas o de militancia en términos más tradicionales.

Los puntos resaltados constituyen una base desde la cual poder introducirnos en un trabajo de campo futuro para ambos casos nacionales con vistas a analizar las concepciones sobre la militancia en actores oficialistas, intentando comprender cómo impacta sobre las mismas un escenario de intensa fluctuación política y desafección ciudadana respecto de los partidos.

Dolores Rocca Rivarola é bolsista de pesquisa pós-doc no Consejo Nacional de Investigaciones Científicas y Técnicas (CONICET), no Instituto de Investigaciones Gino Germani (IIGG) da Universidad de Buenos Aires (UBA). Professora na Facultad de Ciencias Sociales de la Universidad de Buenos Aires. E-mail: doloresrocca@gmail.com

\section{Referencias}

ALTAMIRANO, Carlos. La lucha por la idea: el proyecto de la renovación peronista. In: NOVARO, Marcos; PALERMO, Vicente (comps.). La historia reciente. Argentina en democracia. Buenos Aires: Edhasa, 2004. p. 59-74. 
AMARAL, Oswaldo. Adaptação e resistência: o PT no Governo Lula entre 2003 e 2008. Revista Brasileira de Ciência Política, Brasília, n. 4, p. 105-134, out. 2010a.

As transformações na organização interna do Partido dos Trabalhadores entre 1995 e 2009. 293 f. Tese (Doutorado em Ciência Política) - Programa de Pós-Graduação em Ciência Política, UNICAMP, Campinas, 2010b.

ARMESTO, Melchor; ADROGUÉ, Gerardo. Aún con vida. Los partidos políticos en la década del noventa. Desarrollo Económico, Buenos Aires, v. 40, n. 160, p.619-652, ene.-mar. 2001.

CATTERBERG, Alejandro. Entrevista. 2012. Disponível em: <http://seccionpolitica.com.ar>. Acesso em: 6 de sep. 2012.

CHERESKY, Isidoro. Los desafíos democráticos en América Latina en los albores del siglo XXI. In: CHERESKY, Isidoro (comp.). Elecciones presidenciales y giro político en América Latina. Buenos Aires: Manantial, 2007. p. 19-49.

CARREIRÃO, Yan de Souza. Opiniões políticas e sentimentos partidários dos eleitores brasileiros. Opinião Pública, Campinas, v. 14, n. 2, p. 319-351, nov. 2008.

FABBRINI, Sergio. El ascenso del príncipe democrático. Quién gobierna y cómo se gobiernan las democracias. Buenos Aires: Fondo de Cultura Económica, 2009.

GARCÍA, Raúl Alberto; MONTENEGRO, Néstor (eds.). Hablan los Renovadores. Buenos Aires: Ediciones de la Galera, 1986.

GARRIDO, Natalia. Cibermilitancia 2.0. La juventud kirchnerista en la Argentina de hoy. Sociedad y Equidad, Santiago, n. 4, p. 91-108, 2012.

GORDILLO, Marta; LAVAGNO, Víctor. Los hombres de Perón. El peronismo renovador. Entrevistas inéditas. Buenos Aires: Puntosur, 1987.

GREENE, Steven. Social Identity. Theory and Party Identification. Social Science Quarterly, Norman, v. 85, n. 1, p. 136-153, mar. 2004.

GUIDRY, John A. Not just another labour party. The workers' party and Democracy in Brazil. Labor Studies Journal, Morgantown, v. 28, n. 1, p. 83108, spring, 2003.

HOCHSTETLER, Kathryn; FRIEDMAN, Elizabeth Jay. Representação, partidos e sociedade civil na Argentina e no Brasil. Caderno CRH, Salvador, v. 21, n. 52, p. 47-66, jan.-abr. 2008.

KOLINA. Disponível em: <http://kolina.org.ar/que-es-kolina/>. Acesso em 01 maio de 2013.

LEVITSKY, Steve. Transforming Labor-Based Parties in Latin America. Argentine Peronism in Comparative Perspective. Cambridge: Cambridge University Press, 2003. 
MAINWARING, Scott. Rethinking Party Systems in the Third Wave of Democratization: The case of Brazil. California: Stanford University Press, 1999.

MAINWARING, Scott; TORCAL, Mariano. Party System Institutionalization and party system theory after the Third Wave of Democratization. Kellog Institute Working Papers, n. 319. 2005. Disponível em: <http://kellogg.nd.edu/ publications/workingpapers/WP311_320.shtml>. Acesso em: 02 de ago. 2013.

MANIN, Bernard. Metamorfosis de la representación. In: DOS SANTOS, Mario R. (coord.). ¿Qué queda de la representación política? Caracas: CLACSONueva Sociedad, 1992. p. 09-40.

MONTERO, José Ramón; GUNTHER, Richard. Los estudios sobre los partidos políticos: una revisión crítica. Revista de Estudios Políticos (Nueva Época), Madrid, n. 118, p. 9-38, oct.-dic. 2002.

NOVARO, Marcos. El debate contemporáneo sobre la representación política. Desarrollo Económico, Buenos Aires, v. 35, n. 137, p. 145-157, abr.-jun. 1995. PAIVA, Denise; BRAGA, Maria do Socorro S.; PIMENTEL JR., Jairo Tadeu Pires. Eleitorado e partidos políticos no Brasil. Opinião Pública, Campinas, v. 13, n. 2, p. 388-408, nov. 2007.

PERÓN, Juan D. Conducción Política. Buenos Aires: Instituto Nacional Juan Domingo Perón de Estudios e Investigaciones Históricas, Sociales y Políticas, 2006 [1952].

POUSADELA, Inés. Argentinos y brasileños frente a la representación política. In: GRIMSON, Alejandro (comp.). Pasiones nacionales. Política y Cultura en Brasil y Argentina. Buenos Aires: EDHASA, 2007. p. 125-188.

RIBEIRO, Pedro José Floriano. Algumas notas sobre as eleições brasileiras de 2006: disputa presidencial e reafirmação da força eleitoral do PT. In: SANTANDER, Carlos Ugo; FREIRE PENTEADO, Nelson (org.). Os processos eleitorais na América Latina (2005-2006). Brasília: LGE, 2008. p. 67-89.

ROCCA RIVAROLA, María Dolores. Partidarios del presidente: Un marco conceptual para pensar los conjuntos políticos organizados que sustentaban a Lula y a Kirchner. In: ALACIP - Congreso Latinoamericano de Ciencia Política de la Asociación Latinoamericana de Ciencia Política, 5., Buenos Aires, 2010.

. En torno al líder: Relaciones y definiciones de pertenencia dentro de los conjuntos oficialistas de Luiz Inácio Lula Da Silva (2002-2006) y Néstor Kirchner (2003-2007). 2011. 363 f. Tesis - (Doctorado en Ciencias Sociales) Facultad de Ciencias Sociales, Universidad de Buenos Aires, Buenos Aires, 2011.

La militancia oficialista en Brasil y Argentina a partir de Lula y Kirchner: Hacia un estado del arte. In: Jornadas Interescuelas/Departamentos de Historia. 14., Mendoza, 2013 a. 
. Relaciones y definiciones de pertenencia en los conjuntos oficialistas o bases de sustentación activa de Lula (2002-2006) y Kirchner (2003-2007): Principales argumentos. Temas y Debates, Rosario, 2013b (no prelo).

ROCHA, Daniella de Castro. O Partido dos Trabalhadores em questão. Da lógica militante à lógica do poder? O exemplo do PT na região do Distrito Federal no Brasil (1980-2000). In: Congresso Português de Sociologia, 5., Lisboa, 2008. . Jeunes du Parti des Travailleurs et crise du militantisme. Agora: Débats/jeunesses, Paris, v. 2, n. 52, p. 89-104, 2009.

ROMA, Celso. Organizaciones de partido en Brasil: El PT y el PSDB bajo perspectiva comparada. América Latina Hoy, Salamanca, n. 44, p. 153-184, dec. 2006.

SANTOS, Fabiano; VILAROUCA, Márcio Grijó. Political Institutions and Governability from FHC to Lula. In: POWER, Timothy; KINGSTONE, Peter (eds.). Democratic Brazil Revisited. Pittsburgh: University of Pittsburgh Press, 2008. p. 57-80.

TVPT. Entrevista: Militância virtual agrega militância física, diz blogueiro petista. Disponível em: <www.pt.org.ar>. Acesso em: 10 dez. de 2012.

Texto recebido em 05 de agosto 2013. Aprovado em 16 de agosto 2013. 